\title{
Resilience
}

\section{'Living with the floods': the influence of relational and cognitive capital on disaster risk management capacities in Ratnapura, Sri Lanka}

\section{Nadeera Ahangama, Raj Prasanna \& Denise Blake}

To cite this article: Nadeera Ahangama, Raj Prasanna \& Denise Blake (2018): 'Living with the floods': the influence of relational and cognitive capital on disaster risk management capacities in Ratnapura, Sri Lanka, Resilience, DOI: 10.1080/21693293.2018.1485622

To link to this article: https://doi.org/10.1080/21693293.2018.1485622

曲 Published online: 18 Jun 2018.

Submit your article to this journal $\pi$

Q View related articles $\asymp$

View Crossmark data $\complement$ 


\title{
'Living with the floods': the influence of relational and cognitive capital on disaster risk management capacities in Ratnapura, Sri Lanka
}

\author{
Nadeera Ahangama ${ }^{a}$, Raj Prasanna ${ }^{b}$ and Denise Blake ${ }^{b}$ \\ ${ }^{a}$ Faculty of Graduate Studies, University of Colombo, Colombo, Sri Lanka; bJoint Centre for Disaster \\ Research, Massey University, Wellington, New Zealand
}

\begin{abstract}
Developing multi-stakeholder networks to transfer response and recovery related knowledge between government agencies and flood-prone communities has become an important component of contemporary disaster risk management policy development in South-Asia. Despite the growing desire of governments to engage communities in flood resilience, knowledge of the effectiveness of such measures is still scarce. This research discusses the implications of relational and cognitive social capital on knowledge transfer practices for two disaster risk management stakeholder groups in the Ratnapura district of Sri Lanka. Findings indicate that community stakeholders use social networks within their neighbourhood as a primary survival strategy for 'living with the floods'; however, districtlevel committees find it difficult to facilitate long-term approaches, allocating responsibilities for knowledge transfer and risk reduction. It is concluded that the government efforts to achieve long-term flood resilience goals stand more chance of success if multi-stakeholder networks are capable of bridging this perceptual gap.
\end{abstract}

\section{KEYWORDS}

Disaster risk management; disaster resilience; knowledge networks; relational and cognitive social capital

\section{Introduction}

The United Nations Hyogo Framework for Action 2005-2015 (HFA) (UNISDR, 2005) states that effective disaster management and knowledge networks are essential to building a culture of safety and increased resilience. More recently, the Sendai Framework for Disaster Risk Reduction 2015-2030 (SFDRR) (UNISDR, 2015), similarly endorses the importance of enhancing traditional knowledge exchange and dissemination of disaggregated data amongst communities. In line with these international policy recommendations, developing multi-stakeholder networks to transfer response and recovery related knowledge has become an essential component of contemporary disaster risk management (DRM) practices (UNISDR, 2015). Although recent literature shows considerable interest in understanding how networks of people disseminate knowledge during natural disasters (Aldrich, 2011; Bodin \& Crona, 2009; Doyle, Becker, Neely, Johnston, \& Pepperell, 2015; Gladfelter, 2018; Hughes \& Evans, 2007; Islam, Ingham, Hicks, \& Kelly, 2018; James \& Irudayaraj, 2014), research focused on the impact of social relationships 
and their interpretations towards knowledge dissemination is still scarce. In addition, there has been no academic inquiry done to understand community resilience implications of recently implemented multi-stakeholder networks by the disaster management authorities in Sri Lanka, and other South Asian countries.

With the above background, this study aims to better understand the implications of social relationships and norms on the transfer of flood response and recovery related knowledge by two distinct DRM stakeholder groups. This study produces an empirical inquiry in Ratnapura district of Sri Lanka, providing insights into current knowledge transfer mechanisms in this context, and the social conditions that influence and impact this. The remainder of the article is organised as follows: first, the article introduces definitions of the terminologies used in this study and the study background; second, the methodological approach section discusses the research design and the data collection methods; third, the data analysis section explains processes used to analyse the data and lists the emerged codes; fourth, the findings and discussions section presents the results of the study along with the elaborations of the contributions made to the literature; finally, the article concludes with a summary of the findings, including policy suggestions for DRM practices in Sri Lanka and similar contexts.

\section{Clarification of terminology}

In this study, resilience is understood as a systems' ability to 'resist, absorb, accommodate to and recover from the effects of a hazard in a timely and efficient manner, including through the preservation and restoration of its essential basic structures and functions' (UNISDR, 2009: p. 24). Knowledge networks, as proposed by Phelps, Heidl, and Wadhwa (2012), represent sets of agents and knowledge repositories that enable acquisition, transfer, and creation of knowledge through social relationships. These knowledge networks are seen as valuable resources that facilitate the conduct of DRM stakeholders in the development of community resilience (Aldrich, 2011). Drawing on Putnam's (1993) theoretical approach, social capital is defined as 'features of social organisation such as networks, norms, and social trust that facilitate coordination and cooperation for mutual benefit' (p. 67). Nahapiet and Ghoshal (1998) classified the features of social capital into three distinguishable dimensions: structural, relational and cognitive. Nahapiet and Ghoshal (1998: p. 244) defined the structural dimension as 'the impersonal configuration of linkages between people or units'. The relational dimension describes the kind of personal relationships individuals have developed with each other through a history of interactions (Granovetter, 1992b; Nahapiet \& Ghoshal, 1998). Relational aspects are concerned with normative dimensions such as trust and reciprocity, which guide and influence behaviour. Coleman (1990) explained that an individual actor does not possess norms, but instead these are produced through relationships. Thus, for Putnam (1993), norms of trust encourage cooperation, which in turn lead to increased levels of trust. Correspondingly, reciprocity works like an obligation, which through positive feedback can lead to further reciprocal behaviours. The cognitive dimension of social capital includes the shared meanings and interpretations between parties in a relationship. This dimension was further understood as a set of interpretive schemes, codes and languages that agents from the same network share and refer to in making sense of the behaviour of actors in their environment (Nahapiet \& Ghoshal, 1998). 


\section{Study background}

The Indian Ocean tsunami, which struck Sri Lanka in 2004, killing over 50,000 people, led the Parliament to enact the Sri Lanka Disaster Management Act (SLDMA) in 2005. A disaster management committee (DMC) was established to implement the functions outlined in the SLDMA to ensure the protection of community and environment from further disasters. The DMC lead the strategic planning process for prevention, mitigation, response and recovery. To unify disaster risk managment efforts, the DMC charted a comprehensive National Disaster Risk Management Framework (NDRMF) to detect and coordinate multi-stakeholder efforts across the regions of Sri Lanka. The NDRMF is a holistic strategy that takes on board the recommendations of both the Hyogo and Sendai frameworks, covering the roles and responsibilities of the central government, local government and civil communities (DMC-SL, 2005).

Sri Lanka divides local government into two parallel structures, the provincial councils and the civil service. There are nine elected provincial councils across Sri Lanka, which are led by Chief Ministers. The civil service structure is divided into 25 districts; each has an appointed district secretary. Each district has several divisions, with each division also having a divisional secretary. The civil service structure manages the village level with Grama Niladari (Village Officers) and Samurdhi Niladari (Development Officers), who report to the divisional secretary.

DRM action plans for each district are based on the NDRMF and aim to strengthen disaster resilience in the civil service structure. These district-level DRM action plans recommend that there are disaster stakeholder networks in each district, known as District Disaster Management Coordinating Units (DDMCUs). DDMCUs operate as inter-institutional networks to link district secretariats, divisional secretariats, Grama Niladari, Samurdhi Niladari, the DMC, armed forces and other relevant institutions (DMC-SL, 2005). The DDMCU has the exclusive responsibility of enacting the DMC's DRM strategies.

While DDMCU manages local disasters in local government jurisdictions, community resilience is promoted through village-level networks (undertaking community-based DRM). The DMC initiates the development of civil networks, known as Community-Based Disaster Management Committees (CBDMCs) in villages, which are led by Grama Niladari officers. CBDMCs are comprised of volunteers, village leaders and community members. These civil networks are expected to lead disaster preparation, response and relief, while the DMC and the DDMCUs provide guidelines, training and the necessary facilities for the establishment and maintenance of CBDMCs.

\section{Study location and flood events}

This study focused on the DDMCU in the Ratnapura district and the CBDMC in the Marapana village, situated in Palmadulla division. As depicted in Figure 1, the Ratnapura district is located to the southwest and south of the Central Highlands of Sri Lanka. General rainfall records indicate an average annual rainfall of $3,800 \mathrm{~mm}$. The lowlands of Ratnapura include two main river basins, Kalu and Walawe. 'Kalu' (the black river) is the second largest river basin in Sri Lanka, spanning $2,766 \mathrm{~km}^{2}$ of the western slope of the central hills (Ampitiyawatta \& Guo, 2009) and flows through Ratnapura and Kalutara districts. Both Kalu and Walawe river basins are known to be extremely vulnerable to 


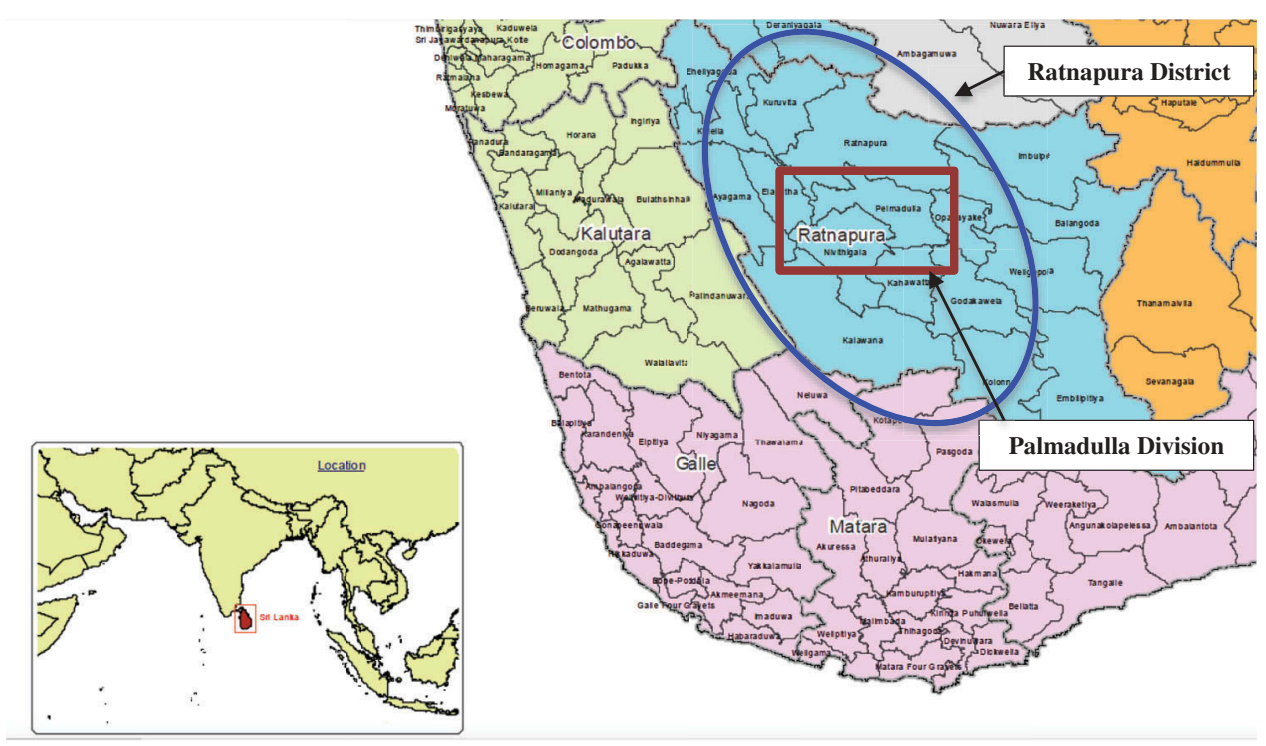

Figure 1. Adapted from 'Map 1: Province, District and DS Division Boundaries of Sri Lanka' by Statistics.gov.lk, 2013 (http://www.statistics.gov.lk/misc/Map\%20of\%20Admin istrative\%20District. pdf).

frequent flooding, and the people of the Palmadulla, Alapatha and Kiriella divisions of the Ratnapura district experience floods every year. The Palmadulla division has recorded significant intense flooding for many years. Geologically, Palmadulla is situated in an ancient floodplain which is comprised of gem-bearing river gravels. Excessive gem mining has worsened the flood situation in this area.

The Ratnapura district has the highest number of flooding incidents in the past decade, with 80 floods occurring between 1999 and 2011 (DMC-SL., 2012). These floods occur during the southwest monsoon (May to June) and the inter-monsoonal season (September to October). Floods significantly affected Ratnapura in 1913, 1940, 1941, 1989, 2003 and 2016. The May 2003 flood caused 122 deaths, affected 34,473 families and caused damage estimated at 1,140 million Sri Lankan Rupees (Rajapakse, 2007). The May 2016 flood affected 14,031 individuals and damaged 287 homes (Relief Web, 2016). The flood situation is particularly devastating in this area because approximately half of the population live on a floodplain, and despite recurrent floods, residents are reluctant to leave their traditional dwellings.

\section{Methodological approach and data collection methods}

This study employs the process of building theory from case study research, as proposed by Eisenhardt (1989), to study the two exploratory case studies. However, considering the theoretical and methodological complementarity of grounded theory methods (GTM) for the data analysis of interpretive case studies (Andrade, 2009; Urquhart, 1999, 2013), the Glaserian strand of GTM (Glaser \& Strauss, 1967) was specifically used to drive the analysis to arrive at stronger conceptual conclusions. While the case study approach of Eisenhardt (1989) helped to provide a systematic procedure for understanding 
participants' experiences, the rigorous analytical procedures developed in GTM (Glaser \& Strauss, 1967) facilitated cross-case analyses of the study themes. We applied critical case sampling, a purposeful strategy that looks for particularly important cases (Patton, 1990) to select the two cases and the participants. The Ratnapura DDMCU and CBDMC of Marapana village of Palmadulla were chosen purposively considering the criticality of the impacts from the recent flood incidents. Participant observation was employed as the primary data collection method. The data collection team was comprised of the lead researcher and two research assistants. This three-member data collection team observed the two disaster drill exercises, having secured the principle agreement from the DMC and DDMCU of Ratnapura.

A tabletop simulation exercise, conducted in January 2016, at the district secretariat office of the city of Ratnapura, was used to gather data for the Case 1. Eighty-five districtlevel DDMCU members designated for flood response and relief activities in Ratnapura district participated. The DDMCU of Ratnapura district was established in early 2000 and serves as the primary government representative for DRM. The tabletop exercise used an extended flood scenario and hypothesised pre-assigned incident command system duties. Participants arranged themselves into four steering committees: operations, planning, logistics and finance/admin. Participants were aged between 35 and 55 years, and most were Sri Lankan Sinhalese. All participants held executive positions in the civil service structure. All participants had secondary or tertiary education, $64 \%$ were men.

The data for Case 2 was based on a village flood map development exercise executed by the CBDMC of Marapana village of Palmadulla, situated in a high flood zone. The map development exercise was conducted in July 2016 in the Marapana village temple with 32 community leaders appointed by the DDMCU of Ratnapura. The case participants were aged between 35 and 70 years and were all Sinhala Buddhists. About $60 \%$ of the participants were literate and had attained junior school education, $80 \%$ were women.

\section{Data analysis}

The project deployed a three-stage grounded theory analysis process (see Figure 2), based upon verbal and non-verbal observations with a focus on participants' meanings. The coding process commenced with the line-by-line coding, and the process developed 70 open codes. The level of complexity of open coding was reduced by classifying the open codes into two core categories: 'knowledge networking' and 'relational and cognitive capital'. While this process produced two primary finding streams, the selective coding process continued until six key themes emerged. Figure 3 depicts the organisation of these themes classified under the two core categories.

As the final step of the coding process, theoretical coding helped to identify and explain the relationships between the themes which emerged and to propose a theoretical model.

\section{Findings and discussions}

This section presents the findings of this study under two main discussion points. First, the themes of the 'knowledge networking' core category are used to discuss the effects of associations on knowledge diffusion. Secondly, the relationship between 'knowledge networking' and 'relational and cognitive capital' is elaborated by discussing the effects 


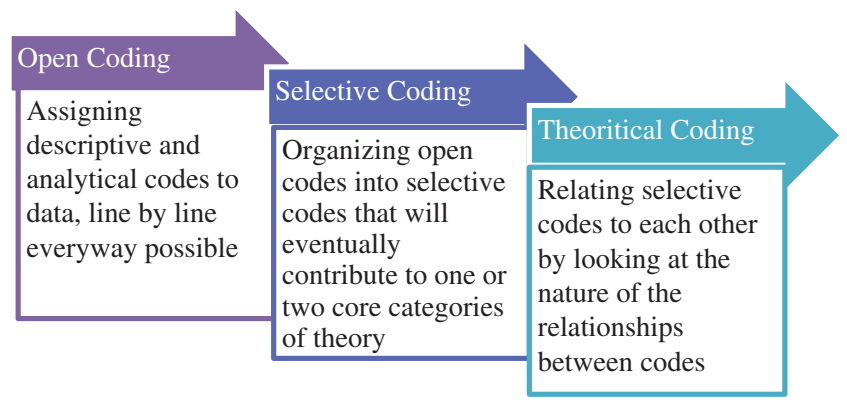

Figure 2. The Three Stage Analytical Path followed in this research.

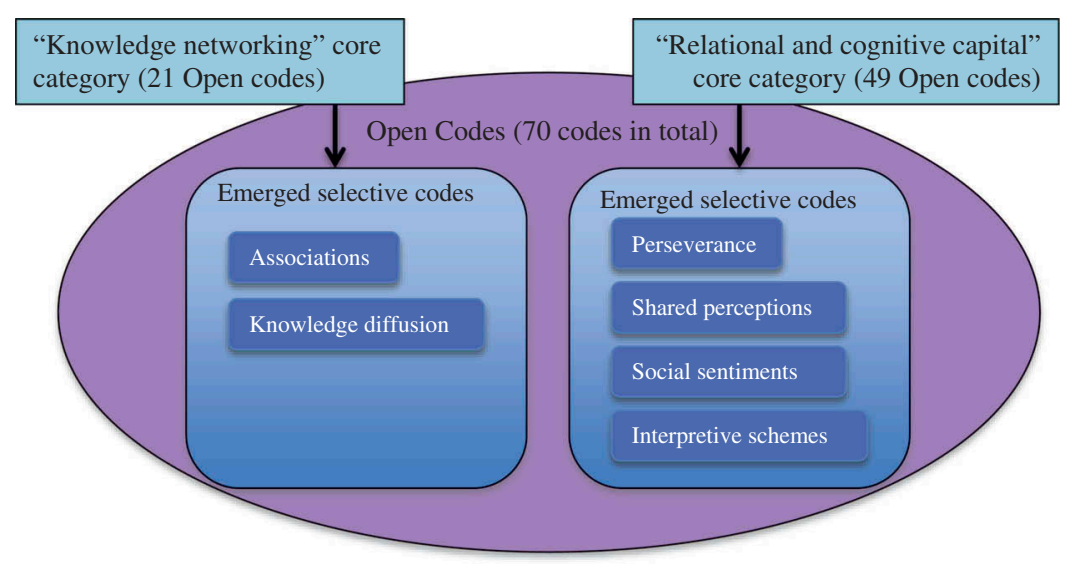

Figure 3. Two Core Categories of Open Codes and Selective Codes Emerged.

of relational and cognitive capital on associations. Finally, this section elaborates on the proposed conceptual framing of 'Social Knowledge Capital' (the SoKap model) which emerged as the outcome of the theoretical coding.

\section{Effects of associations on knowledge diffusion}

Participants of both case studies used formal and voluntary associations with other stakeholders as the key strategy to diffuse knowledge during floods. Although participants described alternatives to support knowledge diffusion such as mass media and evacuation circulars, associations in their social networks served as the critical aspect in their coping strategies. One of the prominent observations in Case 1 was that stakeholders were actively engaged in developing bonding connections in order to transfer knowledge within their team, and establish bridging connections with other government agencies. Alongside the formal meetings to enhance sharing, several informal personal associations created opportunities to broker knowledge amongst stakeholders at state, district and divisional levels. But interestingly, only a few bridging relationships were seen between the community and the DDMCU. 
Participants of Case 2 prominently demonstrated effective knowledge diffusion through voluntary community networks based on the personal relationships. For some participants of Case 2, these community networks influenced whether they evacuated, received temporary shelter, or selected for flood relief assistance, as this was the only knowledge source they had access to. The associations developed with neighbours, friends and family helped them gather details related to the flood, and develop strategies to recover, providing them with physical, emotional and economic support.

Consistent with the extensive body of literature on the positive effects of social networks on knowledge transfer (Aldrich, 2011; Díez-Vial \& Montoro-Sánchez, 2014; Doyle et al., 2015; Hawkins, Maurer, Hawkins \& Maurer, 2010; Huggins, Johnston, \& Thompson, 2012; Inkpen \& Tsang, 2005; Walter, Lechner, \& Kellermanns, 2007), the findings of this study verify that disaster management stakeholders use their bonding associations to enable knowledge diffusion. The findings of Case 1 are also consistent with the concept of 'structural holes' (Burt, 2000) enabling knowledge transfer between communities of stakeholders at state, district and divisional levels. Burt (2000) described a structural hole as a situation in which actors within a cluster are strongly connected to each other but, nevertheless, there are a few 'holes' which link the group to outsiders. For example, some DDMCU participants received flood alerts from the Metrological Department, some from the Irrigation Department and some from community-level responders based on personal or official connections. Even though the stakeholders do not have equal access to knowledge, having a few stakeholders with strong connections allowed members of the DDMCU to capture novel knowledge through structural holes and spread this knowledge through the bonding associations they have built. Having these broker associations added multiple views and enabled the DDMCU to have a better understanding of the flood situation. These results verify the literature (Deeming, 2008; Guarnacci, 2016; Smith \& Boruff, 2011; Yoon, Kang, \& Brody, 2016) that position social associations as a key asset for enabling community resilience and disaster recovery.

However, the current study also develops findings that suggest associations can have a number of negative effects, which also need to be taken on board in the analysis of relational and cognitive capital. This article argues that some associations of participants are negatively affected by the political practices and organisational and culture context. Findings highlight circumstances where clientelist political influences undermined relations of trust and the quality of information flows. Participants highlighted a number of situations where local political leaders attempted to bring their own agendas to DRM processes, having a deleterious effect on policy implementation, and several participants elaborated on situations where political leaders distributed recovery supplies to the party faithful.

Political interference negatively influencing DRM is consistent with literature from Sri Lanka (Senanayake, 2018), Nepal (Gladfelter, 2018), Bangladesh (Islam et al., 2018), Pakistan (Ahmed, 2013), Indonesia (Hayat \& Amaratunga, 2014) and Jamaica (Grove, 2014). Similar to the above findings from developing countries, Vilcan (2017) recently argued that the implementation of resilience initiatives in the UK are also jeopardised by the political contestations played out in them. Apart from the direct impact of political contestation on the implementation of resilience policies, this study presents a contribution to the disaster knowledge management literature as it develops empirical evidence that political influences on associations of disaster stakeholders diminishes 
the quality, accuracy and credibility of disaster knowledge transfer. Participants of both Case 1 and 2 elaborated on circumstances where information and statistics were filtered or changed, thus the reality of disaster situations, as depicted through the knowledge networks, was questioned. These case studies provide evidence that some genuine efforts taken by DDMCU to develop well-informed communities have been undermined by the absence of credibility of their knowledge sources, thereby weakening their capacity for knowledge diffusion within their associations.

Another interesting discussion point revealed from data of this study is the distribution of DRM responsibility between community and governance bodies. In the past decade, Sri Lanka demonstrated a gradual shift from liberal governance practices to the neoliberal implementation of DRM policy by developing community-based associations and transferring some DRM responsibilities to the hands of the community (DMC-SL, 2005). Chandler (2014) and Chandler and Reid (2016) argue that resilience thinking transforms governance practices from 'top-down' liberal forms to more distributed and socially internalised practices such that governance occurs through self-awareness and self-reflexivity. As Chandler and Reid (2016) further suggested, the neoliberal view of governance transfers the responsibility for identifying and solving social problems from the state to the individual.

Democratic literature, under the sway of neoliberal approaches, describes responsibilisation as the process of equal distribution of responsibilities between different actors and social spheres including government, individual citizens, political associations and community (Giddens, 1998; Sevenhuijsen, 2000). Even though Sri Lanka started to demonstrate neoliberal governance policies by establishing and redistributing DRM responsibilities from the DDMCU to the CBDMC, this study questions the effectiveness of such an approach.

The case studies revealed that the committees had conflicting views relating to the distribution of responsibility during the flood response. The DDMCU, which operates as the DRM governing body, seemed to have an unrealistic view of their 'accomplishments' relating to the distribution of knowledge transfer responsibilities from the district level to associations at the community level. Many respondents from DDMCU claimed that the whole disaster response and mitigation process was now based upon the network associations they have developed through passing operational knowledge between DDMCU committees and community associations. Additionally, these respondents from DDMCU stressed that they had taken sufficient attempts to develop local capacities regarding resources and knowledge so that each stakeholder group could now manage its own disaster risk when facing a flood. The DDMCU commonly believed that they had produced a sufficient response and mitigation effort, but were critical of community members, seen to be highly dependent on flood relief donations rather than taking on their individual responsibility for future flood mitigation. Unsurprisingly, participants in Case 2, the CBDMC, argued that, on the contrary, community members did not receive a sufficient level of support from the DDMCU or any other government agency.

Vilcan (2017) articulated a similar situation related to flood groups in the UK, where DRM policy related to the formation and operation of CBDMC made the assumption that actions aimed at raising the awareness of CBDMC members would then trickle down the knowledge to the rest of the community. Vilcan argues that policies articulated on the basis of this assumption make the system unable to capture tensions that arise between 
the community and the CBDMC members. Similarly, in this study, many community members argued that, though committees such as CBDMCs are formed, when it comes to a real disaster situation, the community was left to handle the situation on their own. This study encountered several community members who had received no formal warning of impending flooding, flatly contradicting the assumptions made by the DDMCU. Instead, community members relied entirely on their local knowledge and bonding associations to adjust to short-term survival during flood situations but keeping them far from attaining long-term resilience goals.

Community members also criticised the difficulties of approaching the government for flood relief donations. Some participants of Case 2 claimed that they had not received any physical, emotional or information support from government agencies. Most participants of Case 2 described how they had learnt to face flood situations by applying their own short-term safety measures with the help only from the community knowledge of neighbours, friends, family, religious and societal associations, which they have developed within their community. Thus, the current study complements the findings of some previous research, emphasising the difficulties related to the distribution of responsibility between community and government agencies (Johnson \& Priest, 2008; Saldana-Zorrilla, 2015), governance and policy alignment issues in inter-institutional practices (Hwacha, 2005; Singh-Peterson, Salmon, Baldwin, \& Goode, 2015), overlapping roles and responsibilities, lack of coordination and linkages between different stakeholders (Ahmed, 2013; Fakhruddin \& Chivakidakarn, 2014) and a lack of technical and administrative capacity (Saldana-Zorrilla, 2015).

This study presents a contribution to the literature, revealing a perceptual gap between the DDMCU and the CBDMC in relation to responsibilisation. Although the DDMCU was established in order to take measures to improve local preparedness, save lives and provide resources for rehabilitation, most of the participants from the CBDMC did not perceive that the contributions of the DDMCU were helpful for their response and recovery. Ironically, while participants from the DDMCU were aware that community members used local knowledge and resources to respond to floods, they argued that community members had a donation-dependent mentality and low levels of resilience. It was found that each group carried out their own response and mitigation activities (bonding), but the participatory intervention between the two groups (brokerage) was very limited. The interesting question that arises from this observation is 'Why don't the community and the government agencies appreciate each other's response and mitigation efforts?' Another way to pose this question is 'Why are participants comfortable with bonding knowledge links, but not with brokering links?'

Some scholars have suggested that the unwillingness of communities to share responsibility with external agencies is a reason for this disconnect (Collins, Glavovic, Johal, \& Johnston, 2011; Saldana-Zorrilla, 2015; Scolobig, Prior, Schröter, Jörin, \& Patt, 2015). Another set of researchers have argued that the distance between the two stakeholder levels has increased because government representatives are unable to deliver the support expected by the community (Berke, Chuenpagdee, Juntarashote, \& Chang, 2008; Houston, Spialek, Cox, Greenwood, \& First, 2014; Scolobig et al., 2015). For some analysts, the fault lies with the reluctance of communities to become more engaged and responsible for flood response and mitigation (Bubeck, Botzen, Kreibich, \& H. Aerts, 2012; Manen, 2014). On the other hand, many scholars appreciate the efforts and engagement of communities through local 
knowledge and community associations (Begg, Ueberham, Masson, \& Kuhlicke, 2017; Hawkins \& Maurer, 2010; Islam et al., 2018). The problem, as suggested by a large body of literature, therefore, lies in the implementation of neo-liberal policies by national and local governments in many countries. In fact, several scholars claim that government agencies at state, district or municipals levels are passing on responsibilities under the guise of resilience thinking but without establishing sufficient capacity and procedures to distribute risk responsibility between communities and government agencies (Ahmed, 2013; Becker, 2012; Hwacha, 2005; Islam et al., 2018; Purdue, 2001; Saldana-Zorrilla, 2015; SinghPeterson et al., 2015; Vilcan, 2017).

The findings of this study indicate that the lack of understanding of the community's relational and cognitive capital characteristics is an important reason for the distance between the understanding of the CBDMC and the DDMCU. The lack of understanding between communities and representatives from policy-making bodies is a common finding in many similar studies (Cox \& Perry, 2011; Murphy, 2007; Purdue, 2001; Vilcan, 2017). Vilcan's (2017) findings similarly acknowledged that a clear understanding between local authorities and community play an important role when realising a successful articulation of the chain of responsibilisation to develop community resilience. In neoliberal approaches of governance, the problems related to the responsibilisation are attributed to 'known unknowns' (Chandler, 2014). '[K]nown unknowns' are 'the hidden, underlying, processes of determination, which we know we do not fully know' (Chandler, 2014, p.50). As Chandler (2014) further explained, to overcome problems related to responsibility distribution, such knowledge gaps should be revealed through a deeper sociological understanding of relational and cultural values the of individuals being governed.

Since stakeholders of both levels (community and government agencies) are more receptive to the respective members of their own level (Vilcan, 2017), there is a need of an effective translation medium between different stakeholder groups for multi-stakeholder meetings to understand mental models and relationships between each other. Also future policy implications are required to consider community leaders as the key points of contact bridging the two stakeholder levels (Purdue, 2001). However, mechanisms should also be developed to avoid situations where only a few prominent members of the CBDMC are heard by authorities. Community empowerment should be framed in such a way that DRM responsibility is equally shared between the community and the DDMCU, understanding mental models and relationships amongst stakeholders and encouraging community to take ownership of response, mitigation and recovery rather than relying on state-centric methods. Hence, in the following subsection, this study draws an important link between associations and relational and cognitive capital by identifying several key characteristics such as shared perceptions, social sentiments, interpretive schemes and perseverance to explain the knowledge transfer behaviour of participants.

\section{Effects of relational and cognitive capital on associations}

This study primarily recognises four interrelated themes to explain participants' relational and cognitive capital characteristics. Many researchers recognised that relations between participants (such as trust, respect, friendships and obligations), and the cognitive aspects they share (such as representations, interpretations and systems of meaning) promote engagement between stakeholders (Díez-Vial \& Montoro-Sánchez, 
2014; Doerfel, Lai, \& Chewning, 2010; Inkpen \& Tsang, 2005; Millar \& Choi, 2009; Nahapiet \& Ghoshal, 1998; Oktari, Shiwaku, Munadi, Syamsidik, \& Shaw, 2015; Tsai \& Ghoshal, 1998). Similar to the above research, this article recognises that the relational and cognitive capital of a community positively influences the development of the bonding associations to embrace knowledge transfer during floods. However, this study also recognises the important role of the negative effects of associations in explaining a perceptual gap between the DDMCU and the CBDMC.

The theme of shared perceptions emerged in this study, relating to a learnt set of collective opinions about values, beliefs and the mutual goals of stakeholders. Consistent with the literature on bonding social capital (Bankoff, 2015; Guarnacci, 2016; Nakagawa \& Shaw, 2004), findings from Case 2 highlight that community members perceived the need to react proactively during floods developing locally developed strategies. Trust, sense of belonging, and reciprocity were highly evident between these participants and considered as the main source of strength during early stages of response. The participants of Case 2 perceived flooding as an integral part of their community life. This 'living with the floods' perception of participants led them to develop resourceful collaborations to respond to floods as a community. Consistent with the above literature, findings of this study claim that developed shared perceptions of how to protect themselves during the flood, facilitated the development of effective community associations.

However, as time passes from the initial response phase to the recovery phase, the associative capital that was developed seems to dissipate. When the immediate shock is passed, the participants were less likely to perceive long-term mitigation as a mutual goal of the community, although the same participants perceived a high level of effective resilience through associations during the early phase of the response. Due to perceptual gaps between the DDMCU and the CBDMC, the long-term measures that the government attempted to develop did not have their expected impact. This finding makes a strong case in favour of Bubeck et al. (2012), in emphasising that if the community does not share a risk perception in developing long-term mitigation measures, such communities develop future flood risk. The findings of the study verify the arguments of Bhandari (2014), indicating that bonding links were important for immediate support, but that bridging links offer pathways to long-term mitigation. In agreement with works of Ling and Chiang (2018) and Chiang and Chang (2018) this study suggests that the participants' acceptance of 'living with the floods', while providing collective avenues of immediate response, in fact, actually undermined the recognition of the need for long-term risk adaptation and the perception of a community need to engage more effectively with government agencies.

The theme interpretive schemes, which emerged from the current study, recognise several assigned meanings to social representations and collective meanings shared by CBDMC participants. Similar to the findings of Paton et al. (2010), this study appreciates how community members interpret risk and use community associations to pass knowledge to others. Case 2 uncovers rich indigenous interpretive schemes, which community leaders and villagers used for flood response and communication. CBDMC members believed that even small children were aware of when and how floods occurred, which routes to avoid and the speed of inundations. Villagers had developed indigenous communication and knowledge imparting strategies such as 
hooting, temple bell ringingand observing the sound variation in the river. This study suggests that the cognitive capital of the participants, demonstrated through these interpretive schemes develops the community's ability to communicate and collectively respond effectively. However, findings of this article postulate the need to further develop engagement strategies between the DDMCU and the CBDMC to recognise and to embed these interpretive schemes in local response and mitigation strategies.

Social sentiments is another theme which emerged, it could be defined as the exhibition or manifestation of care and collective concern for disaster-affected communities. Both DDMCU and CBDMC members exhibited social sentiments of compassion and sensibility to disaster-affected communities. Participants frequently connected their actions with principals of Buddhism, and their cultural upbringings. These social characteristics drove participants of both cases to go beyond their comfort zones to help disaster-affected communities. This study highlighted situations where community associations raised massive amounts of flood aid in the form of food, clothes and sanitary goods. Supporting the recent literature (Imperiale \& Vanclay, 2016; Kwok, Doyle, Becker, Johnston, \& Paton, 2016) on community resilience, findings of this study suggest that these social sentiments influenced DDMCU and CBDMC to actively engage in different associations. Hence, this article acknowledges the potential of using the social sentiments of DDMCU members to engage them further in bridging connections with the community.

Both cases disclosed how participants had limited access to physical and technological facilities. Case 1 findings indicated shared concerns of DDMCU members about the working conditions, such as limited facilities, delays in knowledge transfer, the absence of reliable communication, inadequate knowledge of established procedures, long delays in receiving funds and corruption in the political system. Further, the CBDMC members shared concerns about their living conditions. These types of limitations led to inadequate disaster education, unemployment, minimum transportation, inadequate healthcare facilities, unauthorised building constructions, environmental concerns caused by illicit occupations, such as sand mining and gem mining, and disregard for environmental laws. Although Case 1 and 2 highlight challenging social conditions in work and living environments, DDMCU and CBDMC members overcame the threats posed by recent flood situations. The current study recognises perseverance as an important theme. Perseverance describes the steadfastness of participants in facing and adapting to a disaster situation despite difficulties or delays in disaster response mechanisms. The determination or the grit of participants had been developed through associations and had enabled them to continue to achieve disaster response goals. For instance, a community member stated that:

Whenever there is flood, I feel people get an unbelievable strength. Even though our people are poor, when we are together we save our people. I'm a good raft rider. Until I take all the people to the temple side, I will not rest. Everybody works as one. There are no deaths reported for all these years. If we are together, we can. We don't wait till government comes to save us. (Case 2)

During the disaster drill exercise, one of the DDMCU members (Case 1) said:

In these village committees, there are positions like president, secretary, treasurer etc. But when a disaster comes everybody becomes presidents. They work very hard together even without 
much facilities. They find ways to get through. When we go there, they have explored their own ways to save their neighbours (...)

These narratives highlight how the communities come together to respond to a disaster and recover. Both Case 1 and Case 2 provided evidence to show how the stakeholders persevered and strived to minimise disaster loss and damage even if it was challenging. In compliance with resilience literature from Asia (Ainuddin, Aldrich, Routray, Ainuddin, \& Achkazai, 2013; Aldrich, 2011; Bankoff, 2015), the findings of this study suggest perseverance is key to the effectiveness of community associations. However, perhaps even counter intuitively, this study found that the faculty for perseverance could be one of the primary reasons for the perceptual and relational gap between the DDMCU and the CBDMC. Communities have always had to be self-reliant to survive. The more marginal they are the more perseverance is an attribute they have been forced, through the need for survival, to value. Since CBDMC members believed that the DDMCU does not provide them with adequate support, they have continued to develop and rely on their own measures for response and mitigation and to disregard long-term engagement with government agencies, beyond the need for relief requests. If local communities are to be enrolled in long-term mitigation approaches, much will have to be done by DMC and district-level authorities to bridge this perceptual gap.

At the end of the GTM coding process through the theoretical coding, the emerged six themes were synthesised to arrive at the 'Social Knowledge Capital' (SoKap) model of the relationships between the six themes. The SoKap model (see Figure 4) highlights that associations between the two stakeholder groups can facilitate short-term and long-term knowledge diffusion if there exists both bonding (i.e. connections within homogenous social groups) and brokering (i.e. connections between heterogeneous social groups) capital. Further, the SoKap model suggests the need to improve knowledge transfer in contexts where communities demonstrate short-term response mechanisms to survive rather than long-term mitigation approaches. It proposes that the relational and cognitive features of associations could be used to improve knowledge diffusion in environments cluttered with political influences, responsibilisation difficulties, and perceptual gaps between community and governmental agencies.

Relational and Cognitive Capital

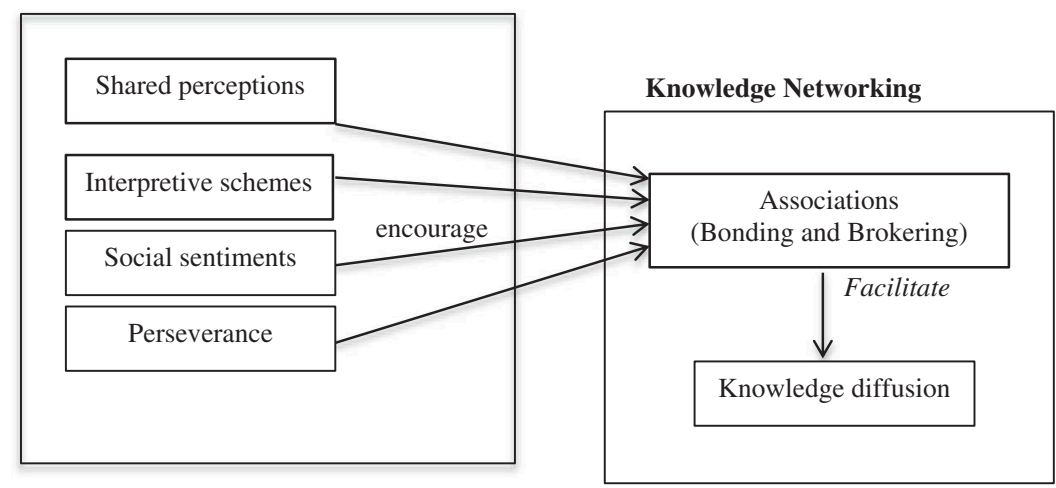

Figure 4. Integrative diagram depicting relationships between themes of SoKap model. 


\section{Conclusion}

In this article, we have analysed how relational and cognitive characteristics of disaster management stakeholders influence the transfer of response and recovery related knowledge in networks during floods. Data were analysed using the method of grounded theory, after observing two disaster drill exercises for two stakeholder groups in Ratnapura, Sri Lanka. This study identifies that stakeholders currently pursue strong perseverance to endure flood situations with the help of bonding relationships at the community level but the existing relational and cognitive distance between government agencies and the community has limited the possibility of knowledge transfer for long-term resilience. This article argues that, if the communities are bonded with strong social capital, but not equipped with brokering connections with government agencies, response mechanisms will be limited to survival rather than long-term mitigation.

The SoKap model, theorised using the emerged themes of this study, proposes a stratagem that could be used in contexts where DRM approaches are predominately confined to short-term proactive measures to survive floods rather than long-term mitigation measures to develop resilience. The findings of this research need to be interpreted in an environment that is significantly influenced by clientelist political attachments, which has developed into perceptual gaps in responsibilisation, and the relational distance between the community and governmental agencies. The proposed model suggests that the government efforts to develop stakeholder associations such as DDMCU and CBDMC will achieve long-term flood resilience goals, only if the gap between government agencies and community members is bridged to enable the transfer of response and recovery related knowledge between the two stakeholder levels. The findings also suggest important policy implications for Sri Lanka's DRM authorities, signalling the urgent need to shift the institutional framework (NDRMF) to enhance the engagement between public- and district-level DDMCUs through developing further brokering knowledge connections. By drawing attention to how the relational and cognitive characteristics such as perceptions and perseverance impact bridging associations negatively during a flood situation, this research emphasises the importance of initiatives to enhance social capital between communities and government agencies.

\section{Disclosure statement}

No potential conflict of interest was reported by the authors.

\section{Notes on contributors}

Nadeera Ahangama is a PhD student at the University of Colombo. She is investigating how disaster related knowledge is disseminated and transformed to other stakeholders and the implications of social relationships and norms on the transfer of response knowledge. In addition to Information systems and disaster resilience, her research interests include Knowledge Management, Green Computing and Technology Management. 
Raj Prasanna is an expert in Technology and Systems for supporting Emergency Management. Raj's current research interests include the application of Internet of Things (IoT) for disaster management, Human Computer Interfaces supporting emergencies and cognitive requirements capturing techniques for emergencies.

Denise Blake has engaged in the social justice sector as health professional and researcher for over 20 years. Her work in the social justice space informs her commitment to the welfare of vulnerable populations both within a disaster context and more generally.

\section{References}

Ahmed, Z. (2013). Disaster risks and disaster management policies and practices in Pakistan: A critical analysis of disaster management act 2010 of Pakistan. International Journal of Disaster Risk Reduction, 4, 15-20.

Ainuddin, S., Aldrich, D. P., Routray, J. K., Ainuddin, S., \& Achkazai, A. (2013). The need for local involvement: Decentralization of disaster management institutions in Baluchistan, Pakistan. International Journal of Disaster Risk Reduction, 6, 50-58.

Aldrich, D. P. (2011). The externalities of strong social capital: Post-tsunami recovery in Southeast India. Journal of Civil Society, 7(1), 81-99.

Ampitiyawatta, A. D., \& Guo, S. (2009). Precipitation trends in the kalu ganga basin in Sri Lanka. Journal of Agricultural Sciences, 4(1), 10-18.

Andrade, A. D. (2009). Interpretive research aiming at theory building: Adopting and adapting the case study design. The Qualitative Report, 14(1), 42-60.

Bankoff, G. (2015). "Lahat para sa lahat" (everything to everybody): Consensual leadership, social capital and disaster risk reduction in a Filipino. Disaster Prevention and Management: an International Journal, 24(4), 430-447.

Becker, P. (2012). The importance of integrating multiple administrative levels in capacity assessment for disaster risk reduction and climate change adaptation. Disaster Prevention and Management: an International Journal, 21, 226-233.

Begg, C., Ueberham, M., Masson, T., \& Kuhlicke, C. (2017). Interactions between citizen responsibilization, flood experience and household resilience: Insights from the 2013 flood in Germany. International Journal of Water Resources Development, 33(4), 591-608. http://doi.org/10.1080/ 07900627.2016.1200961

Berke, P. R., Chuenpagdee, R., Juntarashote, K., \& Chang, S. (2008). Human-ecological dimensions of disaster resiliency in Thailand : Social capital and aid delivery. Journal of Environmental Planning and Management, 51(2), 303-317.

Bhandari, R. B. (2014). Social capital in disaster risk management; a case study of social capital mobilization following the 1934 Kathmandu Valley earthquake in Nepal. Disaster Prevention and Management: an International Journal, 23(4), 314-328.

Bodin, Ö., \& Crona, B. I. (2009). The role of social networks in natural resource governance: What relational patterns make a difference? Global Environmental Change, 19, 366-374.

Bubeck, P., Botzen, W. J. W., Kreibich, H., \& H. Aerts, J. C. J. (2012). Long-term development and effectiveness of private flood mitigation measures: An analysis for the German part of the river Rhine. Natural Hazards and Earth System Sciences, 12(11), 3507-3518.

Burt, R. S. (2000). The network structure of social capital. Research in Organizational Behavior, 22, $345-423$.

Chandler, D. (2014). Beyond neoliberalism: Resilience, the new art of governing complexity, Resilience, 2(1), 47-63. doi:10.1080/21693293.2013.878544

Chandler, D., Reid, J., \& EBSCOhost. (2016). The neoliberal subject: Resilience, adaptation and vulnerability. London: Rowman \& Littlefield International.

Chiang, Y.-C., \& Chang, H.-P. (2018). Cultural dimensions of risk perceptions: A case study on crossstrait driftage pollution in a coastal area of Taiwan. Journal of Environmental Management, 206, 123-133. 
Coleman, J. S. (1990). Foundations of social theory. Social Forces, 69, 993. http://doi.org/10.2307/ 2579680

Collins, S., Glavovic, B., Johal, S., \& Johnston, D. (2011). Community engagement post-disaster: Case studies of the 2006 matata debris flow and 2010 darfield earthquake, New Zealand. New Zealand Journal of Psychology, 40(4), 17-25.

Cox, R. S., \& Perry, K.-M. E. (2011). Like a fish out of water: Reconsidering disaster recovery and the role of place and social capital in community disaster resilience. American Journal of Community Psychology, 48(3-4), 395-411.

Deeming, H. (2008). Increasing resilience to storm-surge flooding: Risks, trust and social networks. Lancaster: Lancaster University.

Díez-Vial, l., \& Montoro-Sánchez, Á. (2014). Social capital as a driver of local knowledge exchange: A social network analysis. Knowledge Management Research \& Practice, 12(3), 276-288.

DMC-SL. (2005). Towards a safer Sri Lanka a road map for disaster risk management. Colombo: Disaster Management Centre.

DMC-SL. (2012). Hazard profile of Sri Lanka. Colombo: Disaster Management Centre.

Doerfel, M. L., Lai, C.-H., \& Chewning, L. V. (2010). The evolutionary role of interorganizational communication: Modeling social capital in disaster contexts. Human Communication Research, $36(2), 125-162$.

Doyle, E. E. H., Becker, J. S., Neely, D. P., Johnston, D. M., \& Pepperell, B. (2015). Knowledge transfer between communities, practitioners, and researchers: A case study for community resilience in Wellington, New Zealand. Australasian Journal of Disaster and Trauma Studies, 19(2), 55-66.

Eisenhardt, K. M. (1989). Building theories from case study research. Academy of Management Review, 14(4), 532-550.

Fakhruddin, S. H. M., \& Chivakidakarn, Y. (2014). A case study for early warning and disaster management in Thailand. International Journal of Disaster Risk Reduction, 9, 159-180.

Giddens, A. (1998). The third way. The renewal of social democracy. Cambridge: Polity Press.

Gladfelter, S. (2018). The politics of participation in community-based early warning systems: Building resilience or precarity through local roles in disseminating disaster information? International Journal of Disaster Risk Reduction. Advance online publication. doi:10.1016/j. ijdrr.2018.02.022

Glaser, B. G., \& Strauss, A. (1967). The discovery of grounded theory: Strategies for qualitative research. Observations (Vol. 1). New York: Aldine De Gruyter.

Granovetter, M. (1992b). Problems of explanation in economic sociology. In N. Nohria \& R. G. Eccles (Eds.), Networks and organizations: Structure, Form, and Action (pp. 25-56). Boston, MA: Harvard Business School.

Grove, K. (2014). Agency, affect, and the immunological politics of disaster resilience. Environment and Planning D: Society and Space, 32(2), 240-256.

Guarnacci, U. (2016). Joining the dots: Social networks and community resilience in post-conflict, post-disaster Indonesia. International Journal of Disaster Risk Reduction, 16, 180-191.

Hawkins, R., \& Maurer, K. (2010). Bonding, bridging and linking : How social capital operated in New Orleans following hurricane katrina. British Journal of Social Work, 40(6), 1777-1793.

Hayat, E., \& Amaratunga, D. (2014). The impact of the local political and socio-economic condition to the capacity of the local governments in the maintenance of post-disaster road infrastructure reconstruction assets. Procedia Economics and Finance, 18(September), 718-726.

Houston, J. B., Spialek, M. L., Cox, J., Greenwood, M. M., \& First, J. (2014). The centrality of communication and media in fostering community resilience: A framework for assessment and intervention. American Behavioral Scientist, 59, 270-283.

Huggins, R., Johnston, A., \& Thompson, P. (2012). Network capital, social capital and knowledge flow: How the nature of inter-organizational networks impacts on innovation. Industry \& Innovation, 19(3), 203-232.

Hughes, N., \& Evans, R. (2007). Networks, connectedness and resilience. Social Policy and Society, 6 (02), 275. 
Hwacha, V. (2005). Canada ' S experience in developing a national disaster mitigation strategy : A deliberative dialogue approach. Mitigation and Adaptation Strategies for Global Change, 10, 507523.

Imperiale, A. J., \& Vanclay, F. (2016). Experiencing local community resilience in action: Learning from post-disaster communities. Journal of Rural Studies, 47, 204-219.

Inkpen, A. C., \& Tsang, E. W. K. (2005). Social capital, networks, and knowledge transfer. The Academy of Management Review, 30(1), 146-165.

Islam, M. R., Ingham, V., Hicks, J., \& Kelly, E. (2018). From coping to adaptation: Flooding and the role of local knowledge in Bangladesh. International Journal of Disaster Risk Reduction, 10, (December 2017), 0-1.

James, S., \& Irudayaraj, M. J. (2014). Community disaster resilience strategies: Community disaster knowledge, social capital, preparedness and mitigation measures enhance coastal community resilience to natural disasters. Golden Research Thoughts, 4, 3.

Johnson, C. L., \& Priest, S. J. (2008). Flood risk management in England: A changing landscape of risk responsibility? International Journal of Water Resources Development, 24(4), 513-525.

Kwok, A. H., Doyle, E. E. H., Becker, J., Johnston, D., \& Paton, D. (2016). What is "social resilience"? Perspectives of disaster researchers, emergency management practitioners, and policymakers in New Zealand. International Journal of Disaster Risk Reduction, 19, 197-211.

Ling, T.-Y., \& Chiang, Y.-C. (2018). Strengthening the resilience of urban retailers towards flood risks - A case study in the riverbank region of Kaohsiung City. International Journal of Disaster Risk Reduction, 27(December2017), 541-555.

Manen, S. M. van. (2014). Hazard and risk perception at turrialba volcano (Costa Rica); implications for disaster risk management. Applied Geography, 50, 63-73.

Millar, C. C. J. M., \& Choi, C. J. (2009). Networks, social norms and knowledge sub-networks. Journal of Business Ethics, 90(SUPPL. S4), 565-574.

Murphy, B. L. (2007). Locating social capital in resilient community-level emergency management. Natural Hazards, 41(2), 297-315.

Nahapiet, J., \& Ghoshal, S. (1998). Social capital, intellectual capital, and the organizational advantage. Academy of Management Review, 23, 242-266.

Nakagawa, Y., \& Shaw, R. (2004). Social capital: Amissing link to disaster recovery. International Journal of Mass Emergencies and Disasters, 22(1), 5-34.

Oktari, R. S., Shiwaku, K., Munadi, K., Syamsidik, \& Shaw, R. (2015). A conceptual model of a schoolcommunity collaborative network in enhancing coastal community resilience in Banda Aceh, Indonesia. International Journal of Disaster Risk Reduction, 12, 300-310.

Paton, D., Sagala, S., Okada, N., Jang, L.-J., Bürgelt, P. T., \& Gregg, C. E. (2010). Making sense of natural hazard mitigation: Personal, social and cultural influences. Environmental Hazards, 9(2), 183-196.

Patton, M. (1990). Qualitative evaluation and research methods. Qualitative evaluation and research methods. Beverly Hills, CA: Sage.

Phelps, C., Heidl, R., \& Wadhwa, A. (2012). Knowledge, networks, and knowledge networks : A review and research agenda. Journal of Management, 38(4), 1115-1166.

Purdue, D. (2001). Neighbourhood governance: Leadership, trust and social capital. Urban Studies, 38(12), 2211-2224.

Putnam, R. D. (1993). The prosperous community: Social capital and public life. The American Prospect, 13, 35-42.

Rajapakse, R. M. S. A. B. (2007). Flood hazard mapping project in rathnapura city. Colombo.

Relief Web. (2016). Sri Lanka floods and landslides - situation report 25 may 2016. Colombo: Author.

Saldana-Zorrilla, S. O. (2015). Assessment of disaster risk management in Mexico. Disaster Prevention and Management: an International Journal, 24(2), 230-248.

Scolobig, A., Prior, T., Schröter, D., Jörin, J., \& Patt, A. (2015, June). Towards people-centred approaches for effective disaster risk management: Balancing rhetoric with reality. International Journal of Disaster Risk Reduction, 12, 202-212.

Senanayake, M. (2018). Development, politics and disaster mitigation: A case study of the moragahakanda irrigation project. Procedia Engineering, 212, 1062-1067. 
Sevenhuijsen, S. (2000). Caring in the third way: The relation between obligation, responsibility and care in third way discourse. Critical Social Policy, 20(1), 5-37.

Singh-Peterson, L., Salmon, P., Baldwin, C., \& Goode, N. (2015). Deconstructing the concept of shared responsibility for disaster resilience: A sunshine coast case study, Australia. Natural Hazards, 79(2), 755-774.

Smith, H., \& Boruff, B. (2011). Recovery from the storm: Resilience and the role of community capital in long-term disaster recovery in regional Western Australia. In State of Australian cities national conference, November 2011. Melbourne, Australia: State of Australian Cities National Conference.

Tsai, W., \& Ghoshal, S. (1998). Social capital and value creation : The role of intrafirm networks. The Academy of Management Journal, 41(4), 464-476.

UNISDR. (2005). Hyogo framework for action. Kobe, Hyogo: Author.

UNISDR. (2009). Terminology. Retrieved January 12, 2015, from http://www.unisdr.org/files/7817 UNISDRTerminologyEnglish.pdf

UNISDR. (2015). Sendai framework for disaster risk reduction 2015-2030. Geneva, Switzerland: Author.

Urquhart, C. (1999). Themes and strategies in early requirements gathering : An investigation into analyst - client interaction. Hobart: University of Tasmania.

Urquhart, C. (2013). Grounded theory for qualilitative research - A practical guide. London: Sage Publications.

Vilcan, T. (2017). Articulating resilience in practice: Chains of responsibilisation, failure points and political contestation. Resilience, 5(1), 29-43.

Walter, J., Lechner, C., \& Kellermanns, F. W. (2007). Knowledge transfer between and within alliance partners: Private versus collective benefits of social capital. Journal of Business Research, 60(7), 698-710.

Yoon, D. K., Kang, J. E., \& Brody, S. D. (2016). A measurement of community disaster resilience in Korea. Journal of Environmental Planning and Management, 59(3), 436-460. 